\title{
COMOS UTILIZAR OS JOGOS DIGITAIS NO CONTEXTO EDUCATIVO: UM ESTUDO DE CASO NUMA ESCOLA DO ENSINO FUNDAMENTAL
}

\author{
Monique Santos de Santana ${ }^{1}$; Solange Mary Moreira Santos²; Maísa Lis Costa dos \\ Santos $^{3}$ \\ 1. Bolsista FAPESB, Graduanda em Licenciatura em Pedagogia,Universidade Estadual de Feira de Santana, e-mail: \\ monisks@hotmail.com \\ 2. Orientadora, Departamento de Educação, Universidade Estadual de Feira de Santana, e-mail: \\ solangemmsantos@gmail.com \\ 3. Bolsista PIBIC/CNPq, Graduanda em Licenciatura em Pedagogia, Universidade Estadual de Feira de Santana, e-mail: \\ maiisacliis@hotmail.com
}

PALAVRAS-CHAVE: TICs, Jogos educativos digitais, práticas pedagógicas.

\section{INTRODUÇÃO}

As mudanças ocorridas a partir da disseminação das Tecnologias da Informação e Comunicação - TICs tem redefinido a vida social e cultural dos indivíduos, proposta por meio de trocas infinitas nas redes. Essas mudanças colocam, também, as crianças em contato com os meios de comunicação digital, que por sua vez, vem aumentado às formas de pensar e agir com autonomia, favorecendo o surgimento de novas competências impactadas pelo avanço tecnológico (BELLONI, 2005).

Os modos com que as tecnologias vêm expandindo seu espaço nas atividades cotidianas dos seres humanos têm proporcionado, também, novas formas de se pensar a educação de crianças e jovens que estão cada vez mais fascinados pelos recursos oferecidos por máquinas que os deixam conectados em tempo real com o mundo virtual, uma vez que esses sujeitos são considerados nativos digitais por terem nascidos na era das TICs.

Para Carniello, Rodrigues e Moraes (2010), os nativos digitais apoderam-se das TICs como parte integrante da sua construção como indivíduo, visto que na realização de suas tarefas cotidianas utilizam das ferramentas tecnológicas para concretizar atividades de interação com amigos, pesquisas, diversão, entre outros. Desse modo, a relação estabelecida por crianças e jovens com o mundo virtual, possibilita que a educação se aproprie desse diálogo entre os sujeitos e as TICs, para inovar práticas pedagógicas na escola.

Dentre as atividades que as crianças e os jovens utilizam em momentos de lazer e, que ao mesmo tempo os colocam em contato com outros sujeitos, estão as atividades com características lúdicas como o jogar. O jogo exerce uma função predominante na cultura contemporânea, por ser tão extensivo quanto às noções de brincar, no qual tem sido usado frequentemente para definir passatempos e divertimentos, sendo a regra uma de suas características (PORTO, 2008). A esse respeito, a presença da ludicidade na vida do educando pode apresentar caminhos que favoreçam o seu processo de aprendizagem, permitindo assim, que se busquem também novas formas de aprendizagem mediadas pela presença das TICs na educação.

Para Porto (2012), as tecnologias possibilitam o enriquecimento do processo pedagógico ao colocar professores e alunos no mesmo contexto de navegação e exploração, proporcionadas pelas TICs, que resultem em aprendizagens variadas. Dentro do contexto das atividades lúdicas educacionais, que incluem a utilização de jogos, Savi e Ulbricht (2008), asseveram que os jogos digitais podem ser uteis para o desenvolvimento de práticas atrativas e inovadoras que possibilite aos alunos aprenderem de forma mais dinâmica e motivadora.

Diante das possibilidades que os instrumentos tecnológicos propiciam para informação e comunicação dos sujeitos, o professor pode aproveitar-se dessas ferramentas e empregá-las 
como recursos que visam potencializar o desenvolvimento dos alunos, mediante a inovação de práticas pedagógicas para um ensino com mais interatividade. A partir dessas considerações, esta investigação objetivou analisar a inserção dos jogos digitais nas atividades pedagógicas, identificar quais recursos tecnológicos estão sendo utilizado para promover a utilização dos games nos espaços escolares, bem como discutir o uso dos jogos digitais no Ensino Fundamental. Para tanto, utilizamos das contribuições teóricas de alguns autores, tais como, Belloni (2005), Carniello Rodrigues e Moraes (2010), Gee (2009), Porto (2008), dentre outros, que discorrem sobre as TICs e a utilização dos jogos digitais nas práticas educativas.

\section{METODOLOGIA}

A proposta de atividade que contemplou esta investigação foi a elaboração e execução de oficina, pautada na utilização dos jogos digitais educativos, tendo como base os estudos realizados, que abordavam a utilização de jogos online no processo de ensino aprendizagem. Desse modo, a pesquisa realizada neste estudo foi de abordagem qualitativa do tipo descritiva, tendo em vista que a mesma descreveu a complexidade de determinado problema, analisou a interação de certas variáveis, compreendeu e classificou processos dinâmicos vividos por grupos sociais.

$\mathrm{Na}$ perspectiva dos estudos qualitativos, a pesquisa foi desenvolvida com estudantes do Ensino Fundamental, em um dos espaços escolares da rede pública de ensino, no município de Feira de Santana/Ba. Na implementação da oficina os alunos participes da pesquisa se engajaram nas atividades propostas e no desenvolvimento de procedimentos crítico-reflexivos sobre interação dos jogos com as atividades curriculares, tomando como base a melhoria da ação prática (ELLIOT, 1998). Diante disso, fez-se necessário o desenvolvimento de uma dinâmica coletiva, que permitisse o estabelecimento de referências continuas e evolutivas, no sentido de apreensão dos significados construídos e em construção (THIOLLENT, 1986).

No momento da oficina foram utilizados como instrumento para coletas de dados, dois questionários, um versando sobre a utilização de jogos computacionais e o outro tratando de avaliação dos participantes da oficina, referente ao jogo aplicado na atividade realizada. Além disso, outro dispositivo metodológico utilizado consistiu no ato de observar, visto que foram considerados aspectos importantes para a análise às formas como os alunos se posicionaram diante da ludicidade utilizada para dinamizar aprendizagem, suas expectativas, a avaliação da ação, a relação que estabelece com os pares e a circulação de informações elaboradas no coletivo.

\section{RESULTADOS}

Com base nos estudos elencados sobre os jogos online educativos, fez-se necessário avaliar o sentido do emprego dos jogos online nos espaços educacionais, tendo em vista que o mesmo trata-se de um recurso lúdico que pode se tornar um mecanismo de inovação na prática pedagógica, por dinamizar a didática da sala de aula e possibilitar aos alunos uma aprendizagem consistente e prazerosa. Com a utilização dos jogos pode surgir novas possibilidades do aluno desenvolver habilidades e competências que descaracterizem a dificuldade em se aprender os conteúdos curriculares. Essa avaliação se deu a partir o desenvolvimento de uma oficina intitulada: "Testando o conhecimento", abordando o conteúdo sobre a Pré História, da área de conhecimento de História. Essa oficina teve como proposta desenvolver as atividades utilizando-se dos jogos educativos online no ensino fundamental.

A proposta inicial para realização da oficina visava contemplar uma turma do $6^{\circ}$ ano do Ensino Fundamental. Entretanto, só foi viável desenvolver a atividade com 10 alunos do $6^{\circ}$ ano, pois no laboratório de informática possuía apenas 10 computadores, 3 estavam 
configurados com o sistema operacional Windows, então só foi possível utilizar um monitor por máquina, e 7 atuavam com o sistema operacional Linux, conectados por dois monitores simultâneos que possibilitava realizar comandos distintos, somente os equipamentos com o sistema Windows estavam funcionando corretamente. Desse modo, o trabalho foi desenvolvido em grupos o que contribuiu para a interação dos participantes na construção do que foi proposto como atividade.

Durante a realização da oficina, percebemos o envolvimento dos alunos em desenvolver as atividades, principalmente por se tratar de um ambiente fora da sala de aula, mas que pertencia ao contexto escolar que eles estavam inseridos, já que se tratava da sala de informática (computadores, internet, atrativos em destaque entre crianças e jovens).

Os educandos pontuaram que utilizam os jogos digitais frequentemente, o que significa que, o tempo de dedicação que crianças e jovens disponibilizam para realizar esse tipo de atividade, pode ser pensado dentro do contexto educacional, como estratégia de utilização no processo de ensino e aprendizagem, tendo em vista que é possível expandir as variadas funções relativas aos videogames nos processos de ensino desenvolvidos no ambiente escolar, partindo das experiências culturais construídas nas comunidades virtuais de jogadores.

Dentre os jogos que os estudantes mais gostam de jogar estão Minecraft (jogo de construção), que pode ser jogado, também, através da rede social Facebook; GTA (jogo de luta); Criminal Case (jogo de investigação); Minimundos (jogo que cria avatar e interage com outras pessoas online); The Sims; Água e Fogo, entre outros. Esses jogos não são exclusivamente classificados como educativos, porém é possível analisar se os mesmos podem apresentar algum conteúdo que os vincule à prática educativa, na tentativa de potencializar a presença do lúdico nas atividades de cunho pedagógico, vinculados à instituição escolar.

Para Gee (2009), os jogos apresentam princípios, independentemente de serem educativos ou não, que podem tornar a aprendizagem tanto na escola quanto para além dela parecidas com os sentidos pregados pelos jovens aos jogos no modo reflexivo e estratégico. Ou seja, o jogo em sua dimensão vai além da percepção limitada de sua potencialidade, não se restringe a mera aprendizagem de saber jogar os videogames em questão, ele ultrapassa as barreiras do conteúdo a ser aprendido para jogar de maneira repetitiva. O jogo abarca vários tipos de atividades, caracterizadas por ferramentas e linguagens que resultam no conjunto de regras para o desenvolvimento daquela atividade.

O jogo utilizado para que os estudantes colocassem em prática seus conhecimentos solicitava que os jogadores criassem uma história em quadrinho que estivesse relacionado aos estudos sobre a Pré-História. Para isso, os alunos explorariam a imaginação através da montagem dos cenários com os elementos e personagens disponibilizados no aplicativo, desenvolvendo suas habilidades e criatividades. Esse jogo está disponível na internet, em um site que apresenta só games criados com fins educativos. De acordo com Zadona Junior (2012) faz-se "necessário descrever e detalhar a dinâmica do jogo, desde o que será possível desempenhar dentro do ambiente do jogo até os componentes históricos com cenários e enredo que darão suporte à ação do jogador" (ZADONA JUNIOR, 2012, p.89). Nesse sentido, é importante sinalizar qual a finalidade dos jogos para que a sua utilização no processo de ensino aprendizagem seja adequada com a atividade que se pretende realizar.

A realização desta atividade possibilitou aos alunos trabalharem a observação na busca de criarem estratégias para realizar a atividade, além de descreverem quais métodos foram utilizados a partir de suas análises, e como devem desenvolver um trabalho pensado no coletivo. Os alunos evidenciaram que o uso de jogos digitais podem tornar as aulas mais didáticas e interessantes, bem como podem ampliar a interação deles com as tecnologias, que ajudam na aprendizagem. Nesse sentido, podemos considerar que a utilização do jogo tende a 
proporcionar o desenvolvimento de um trabalho interativo e motivador, uma vez que possibilita no processo de ensino e aprendizagem relacionar a proposta do jogo com os conteúdos trabalhados nas diversas áreas de conhecimentos.

\section{CONCLUSÃO}

Com base nos estudos elencados e na realização da oficina percebemos que a utilização de jogos digitais para realização de atividades pedagógicas, podem trazer contribuições significativas no processo de ensino e aprendizagem. Os jogos, de modo geral, fazem parte do cotidiano dos estudantes por proporcionar momentos de diversão, quando esses estão fora ambiente escolar, no qual dedicam boa parte do tempo para o ato de jogar, em que se requer concentração, interpretação e envolvimento dos usuários.

Os games disponibilizados online tem ganhado o interesse do público jovem, pois os colocam em contato com outros sujeitos, em tempo real, dentro do contexto virtual expandido assim, a troca de informação e interação como uma das atividades que promove o desenvolvimento do homem com o meio social.

Diante disso, podemos considerar o universo lúdico da internet como mais um espaço de produção de sentido, que desenvolvem novas formas de conhecimento e de interação, perpassando os espaços concretos, ampliando o campo infinito de opções e de ludicidade do mundo digital e que, o uso de jogos, no processo ensino-aprendizagem pode desenvolver uma maior autonomia em relação às atividades curriculares, além de motivar o interesse e a participação dos alunos nesse processo educativo.

\section{REFERÊNCIAS}

BELLONI, Maria Luiza. O que é mídia-educação. 2 ed. Campinas, SP: Autores Associados. 2005.

CARNIELLO, Luciana Barbosa Cândido; RODRIGUES, Bárbara Mônica Alcântara Gratão; MORAES, Moema Gomes. A relação entre os nativos digitais, jogos eletrônicos e aprendizagem. $3^{\circ}$ Simpósio Hipertexto e Tecnologia na Educação: redes sociais e aprendizagem. Anais Eletrônicos, 2010. Disponível em: $<$ https://www.ufpe.br/nehte/simposio/anais/Anais-Hipertexto-2010/Luciana-Barbosa-

Carniello\&Barbara-Alcantara-Gratao\&Moema-Gomes-Moraes.pdf> Acesso em: março/2017. ELLIOT, J. Recolocando a pesquisa-ação em seu lugar original e próprio. In: GERALDI, C. M. G.; FIORENTINI, D.; PEREIRA, E. M. A. (Orgs.). Cartografias do trabalho docente. Campinas: Mercado da Letras, 1998, p. 137-152.

GEE, JAMES Paul. Bons videogames e boa aprendizagem. PERSPECTIVA, Florianópolis, v. 27, n. 1, 167-178, jan./jun. 2009. Disponível em <http://www.perspectiva.ufsc.br> Acesso: jun/2016.

PORTO, Cristina Laclette, Brincadeira ou atividade Lúdica? In.: Jogos e brincadeiras: desafios e descobertas. Salto para o futuro. 2 2 ed. Ano XXIII boletim 07- Maio de 2008.

PORTO, Tânia Maria Esperon. As tecnologias estão nas escolas. E agora, o que fazer com elas? In.: FANTIN, Monica; RIVOLTELLA, Pier Cesare (Orgs). Cultura digital e escola: Pesquisa e formação de professores. Campinas/SP: Papirus, 2012.

SAVI, Rafael; ULBRICHT, Vania Ribas. Jogos digitais educacionais: benefícios e desafios. Novas Tecnologias na Educação. CINTED-UFRGS. V 6. N 2, 2008.

THIOLLENT, Michel. Metodologia da pesquisa-ação. 7. ed. São Paulo: Cortez, 1986.

ZADONA JUNIOR, Almir. A virtualização do lúdico: o fechamento do universo formativo do brinquedo. Goiania/GO, 2012. Disponível em: < https://ppge.fe.ufg.br/up/6/o/Disserta\%C3\%A7\%C3\%A3o_Almir_Zandon\%C3\%A1_J\%C3 \%BAnior.pdf> Acesso em jun/2017. 